\title{
Friction factor of a meandering open channel flow
}

\author{
S. Moharana, K. K. Khatua \& M. Sahu \\ Department of Civil Engineering, National Institute of Technology, India
}

\begin{abstract}
The usual practice in one dimensional flow analysis is to select an appropriate value of roughness coefficient for evaluating the actual stage-discharge relationship of a natural channel. Reliable estimate of discharge capacity in meander open channel is extremely important from river engineering point of view. It helps the practitioners to provide essential information regarding flood mitigation, construction of hydraulic structures and prediction of sediment load so as to plan for effective preventive measures. Selection of the proper value of friction factor is essential for evaluating the actual carrying capacity of natural channel. An experimental investigation concerning the variation of friction factor for meandering channels with flow depths, aspect ratio, slope and sinuosity are presented. Here an effort has been made based on ANFIS to predict the friction factor of meander channel for both smooth and rough surfaces using the experimental as well as the data sets collected from literature study. Finally the results of the applied method predicts friction factor effectively.

Keywords: meandering channel, sinuosity, stage-discharge relationship, bed slope, flow resistance, aspect ratio, fuzzy logic, fuzzy inference system, roughness ratio.
\end{abstract}

\section{Introduction}

Prediction of flow is an important topic in river hydraulics that needs to be investigated from a practical point of view in relation to flood prediction, the bank protection, navigation, water intakes and sediment transport-depositional patterns etc. It is found that the flow structure of meandering channel is surprisingly more complex than straight channels according to Sellin [1] and Shiono et al. [2], Patra and Kar [3], Patra and Khatua [4], Khatua et al. [5]. 
Usually Chezy's, Manning's or Darcy-Weisbach equation given in Chow [6] is used to calculate the mean velocity of flow in an open channel. The roughness coefficient in these cases is represented as $c, n$ and $f$ respectively. For the proper estimation of discharge in an open channel the single most influencing important parameter is to select a suitable value of roughness coefficient in terms of DarcyWeisbach friction factor f. The basic approach proposed by Cowan [7] was modified by Acrement and Schneider [8]. Army Corps of Engineers (Hydraulic [9]) conducted a series of stage-discharge experiments in meandering channels at the Waterways Experiments Station in Vicksburg. The main purpose of these experiments was to investigate the effect of the geometric parameters on the conveyance capacity of meandering channel. The Soil Conservation Service method [10] is also used for selecting roughness coefficient values for channels. These are found to be discontinuous at the certain limits of the defined sinuosity ranges with consequent ambiguity. James and Wark [11] reviewed the various methods for bend loss in meandering channel proposed by different investigators. He proposed some new methods accounting for additional resistance due to bend by suitable modifications of previous methods. Maria and da Silva [12] expressed the friction factor of rough turbulent meandering flows as the function of sinuosity and position. Shiono et al. [1] reported the effect of bed slope and sinuosity on discharge of meandering channel. On the basis of dimensional analysis, Khatua et al. [5] proposed a mathematical model on the basis of dimensional analysis to predict the roughness coefficient of a meandering channel.

The review shows that the flow in meandering river is influenced by many factors, namely the shape of cross-section, flow depth, sinuosity, Reynolds no, roughness ratio and side slope etc. These factors are assumed to be a single value of resistance coefficient. The review also finds the importance of different hydraulic and geometric parameters influencing the prediction of friction factor of a meandering channel to simulate its stage-discharge relationship. In the present study, using ANFIS (Adaptive Neuro-Fuzzy Inference System) it is attempted to predict a proper value of Darcy Weisbach friction factor $\mathrm{f}$. Where a given input/output data set, the toolbox function ANFIS constructs a Fuzzy Inference System (FIS) whose membership function parameters are tuned using either a back propagation algorithm alone, or in combination with a least squares type of method. The work is also supported by conducting a series of experimentation and also collecting data from different experimental sets of varying geometry, slope, aspect ratio and sinuosity from the literature. The present model is found to predict the friction factor better than that compared to other established methods.

\section{Experimental setup}

The present research uses the meandering experimental channel data recorded from the tilting flume in the Fluid Mechanics and Hydraulics Engineering Laboratory of the Civil Engineering Department, at the National Institute of Technology, Rourkela, India. Observation is made from meandering channel having trapezoidal cross section. The tilting flume is made out of metal frame 


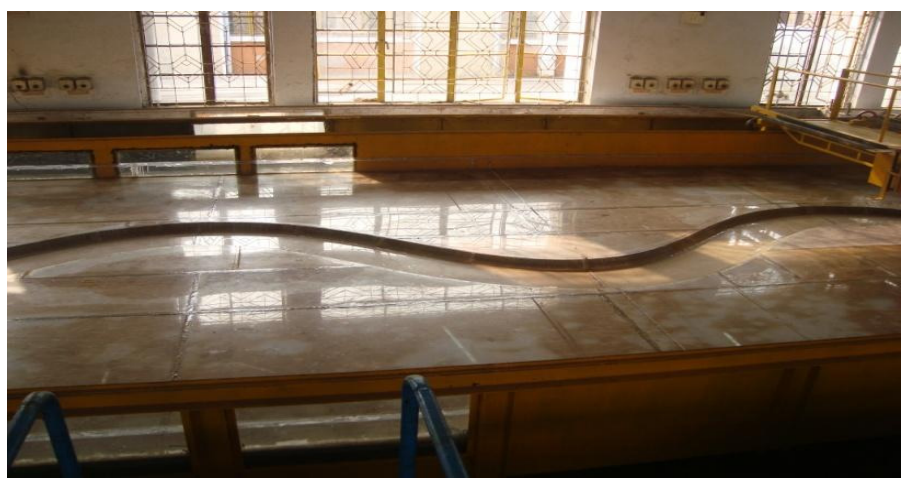

Figure 1: Details of meandering channel with the measuring equipment.

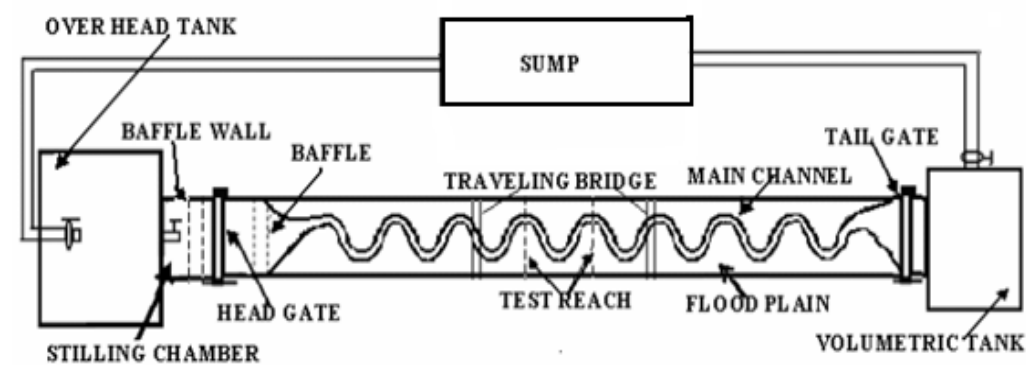

Figure 2: Detailed plan view of meandering channel with measuring equipment.

with glass walls at the test reach. It is tilted by hydraulic jack arrangement. Inside the flume, separate meandering channel is cast using $6 \mathrm{~mm}$ thick perspex sheets. A photograph of meandering channel with measuring equipment taken from the downstream side is shown in Fig. 1 and the sectional plan view is shown in Fig. 2.

Water is supplied to the experimental setup by a re-circulating system. Two parallel pumps are used to pump water from an underground sump to the overhead tank. From the over head tank, water is led to a stilling tank located at the upstream of the channel. A series of baffle walls between the stilling tank and channels are kept to reduce turbulence of the incoming water. At the end of the experimental channel, water is allowed to flow through a tailgate and is collected in a masonry volumetric tank from where it is allowed to flow back to the underground sump. From the sump, water is pumped back to the overhead tank, thus setting a complete re-circulating system of water supply for the experimental channel. The tailgate helps to establish uniform flow in the channel.

Water surface slope measurement is carried out using a pointer gauge fitted to the travelling bridge operated manually having least count of $0.1 \mathrm{~mm}$. Point velocities are measured using a pitot tube at a number of locations across the 
predefined channel section. Guide rails are provided at the top of the experimental flume on which a travelling bridge is moved in the longitudinal direction of the entire experimental channel. The point gauge and a micro-pitot tube of $4.6 \mathrm{~mm}$ external diameter are attached to the travelling bridge can also move in both longitudinal and the transverse direction of the experimental channel at the bridge position. The pitot tube in conjunction with a suitable inclined manometer is used to measure velocity and its direction of flow at the pre defined points of the flow-grid. The pitot tube is physically rotated normal to the main stream direction till it gives maximum deflection of manometer reading. The angle of limb of pitot tube with longitudinal direction of the channel is noted by the circular scale and pointer arrangements attached to the flow direction meter. Discharge in the channel is measured by the time rise method in the measuring tanks located at the downstream end of the experimental channel. A rectangular notch has also been fabricated at the $\mathrm{u} / \mathrm{s}$ which is calibrated to find the continuous stage-discharge relationships of the channels. All observations are recorded at the central bend apex of meandering channels. The geometrical parameters and hydraulic details of the experimental runs are given in Table 1.

Table 1: Details of geometrical parameters of the experimental channels.

\begin{tabular}{|c|c|c|}
\hline Sl No & Item description & Present experimental channel \\
\hline 1 & Channel type & Meandering \\
\hline 2 & Flume size & $4.0 \mathrm{~m} \times 15 \mathrm{~m} \times 0.5 \mathrm{~m}$ long \\
\hline 3 & Geometry of main channel section & Trapezoidal (side slope $1: 1$ ) \\
\hline 4 & Nature of surface of bed & smooth and rigid bed \\
\hline 5 & Channel width & $33 \mathrm{~cm}$ at bottom and $46 \mathrm{~cm}$ at top \\
\hline 6 & Full depth of channel & $6.5 \mathrm{~cm}$ \\
\hline 7 & Bed Slope of the channel & 0.0022 \\
\hline 8 & Sinuosity & 1.12 \\
\hline 9 & Amplitude & $951 \mathrm{~mm}$ \\
\hline 10 & Wave length in down valley direction & $3972 \mathrm{~mm}$ \\
\hline 11 & No of runs for stage-discharge data & 20 \\
\hline
\end{tabular}

\section{Experimental results}

\subsection{Variation of Darcy-Weisbach friction factor $f$}

The present meandering channel is special as compared to the previous channels established in the Fluid Mechanics and Hydraulics Engineering Laboratory of the Civil Engineering Department, at the National Institute of Technology, Rourkela, India. The channel is of low sinuosity i.e. 1.12 (where as previous channels has sinuosity 1.44 and 1.91 respectively) and has a side slope 1:1 with trapezoidal cross-section. Flow depths in the experimental channel runs are carried out by maintaining the water surface slope is parallel to the valley slope. In all the 
experimental runs this simplified approach has been tried to achieve. This stage of flow is taken as normal depth, which can carry a particular flow only under steady and uniform conditions. The stage discharge curves plotted for the channel is shown in Fig. 3.The discharge increases with an increase in stage. The results for variation of friction factor $f$ with depth of flow have also been plotted in Fig. 4. Darcy-Weisbach $f$ is found to decrease with increase of aspect ratio (ratio of width of the channel to the depth of flow) indicating that meander channel consumes more energy as the depth of flow increases. So with increase in aspect ratio, Darcy-Weisbach $f$ decreases. This also varies with slopes (Fig. 5) and sinuosity (Fig. 6). It increases with an increase in both these parameters. For highly sinuous channels and for steep channels the values of $f$ become large

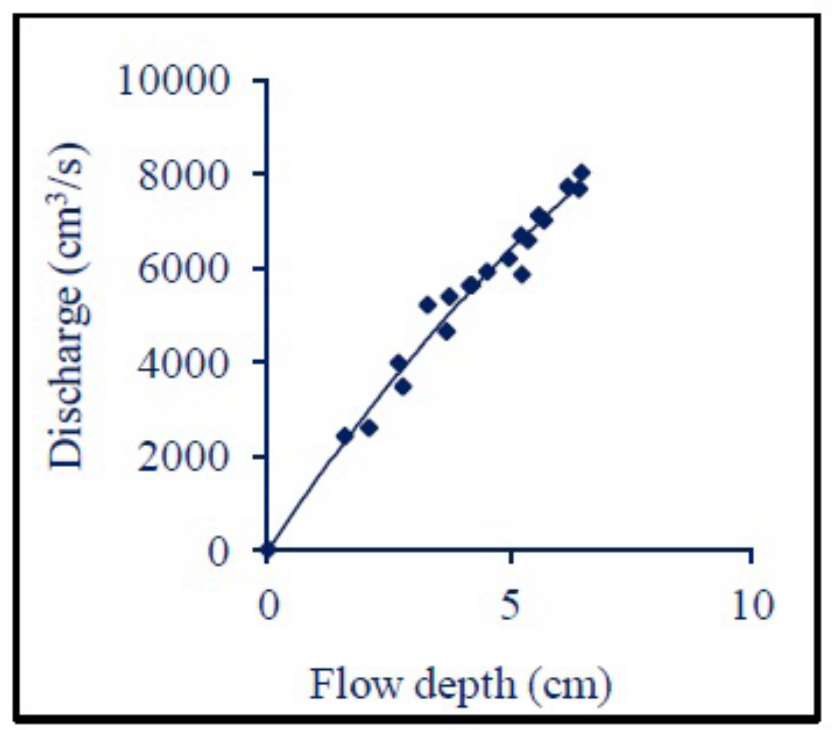

Figure 3: Stage-discharge relationship.

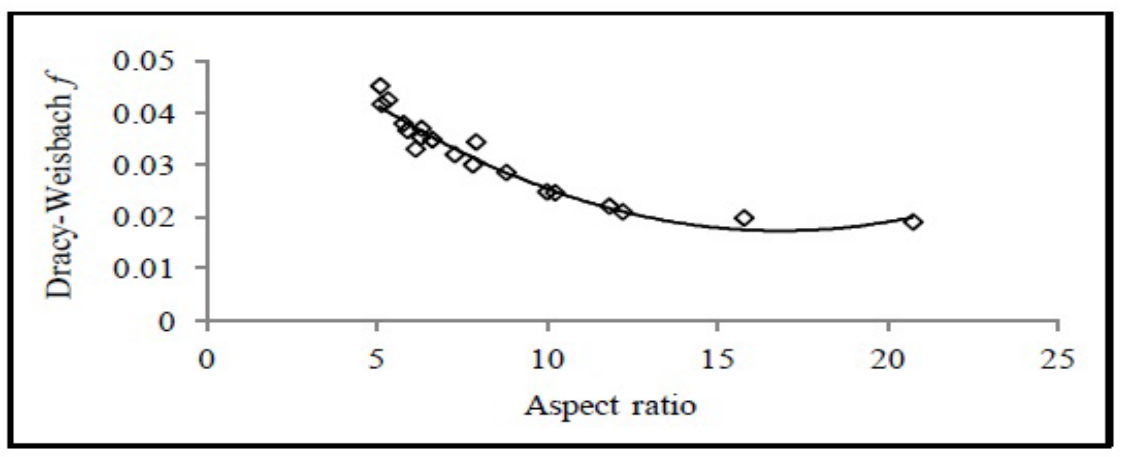

Figure 4: Variation of Dracy-Weisbach $f$ with aspect ratio. 
indicating that the energy loss is more for meandering channels with higher slopes. The effect of side slope also cannot be ignored as compared to vertical sided channels (i.e. rectangular) which can be observed in the Fig. 7. The friction factor is larger for trapezoidal meandering channel as compared to that of rectangular meandering channel. This is because more surface areas come in to account in the case of trapezoidal channel.

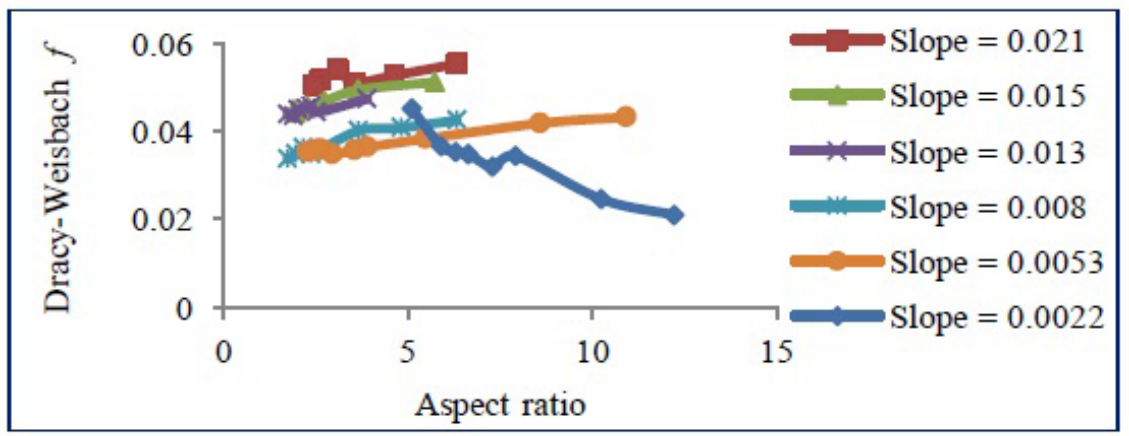

Figure 5: Variation of Dracy-Weisbach $f$ with slope.

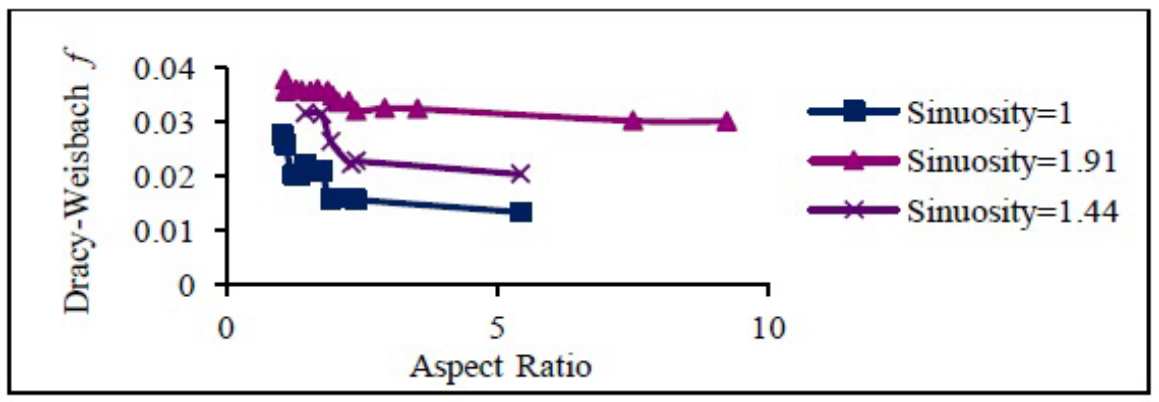

Figure 6: Variation of Dracy-Weisbach $f$ with sinuosity.

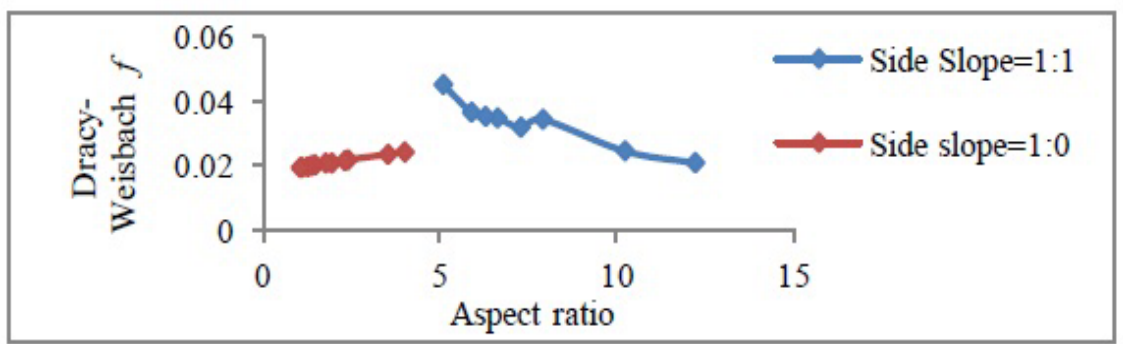

Figure 7: $\quad$ Variation of Dracy-Weisbach $f$ with side slope. 


\subsection{Friction factor in open channel flow}

For the proper estimation of velocity in an open channel section selection of a suitable value of roughness coefficient $\mathrm{f}$ is an important aspect that needs to be addressed properly. Under steady and uniform flow conditions, to compute the section mean velocity carried by a channel section is calculated by the help of Dracy-Weisbach's equation, as

$$
U=\sqrt{\frac{8 g R S}{f}}
$$

where, $S$ = slope of the channel, $g$ = gravitational acceleration, $R=$ the hydraulic mean radius of the channel section, $f=$ the friction factor. This traditional formula is valid for straight channels and gives higher error when applied to meandering channels. As discussed in the literature, different investigators have proposed equation to predict friction factor for meandering channels. The model are fitting to the channels with some particular field condition only and gives error to calculate discharge for the channels with other hydraulics, geometric and surface conditions. Presently rapid development in intelligence computing not only lessening the tedious effort of experimentation but also it eliminates tedious computations. Investigators adopted used back propagation (BP) algorithm of artificial neural network (ANN) for the prediction of roughness in a meandering open channel flow. Adaptive Neuro-Fuzzy Inference System (ANFIS) has been adopted in a variety of fields for accurate prediction of responses in situations where solution is imprecise and uncertain. When relationship between input and output is difficult to establish using mathematical, analytical and numerical methods and it becomes cumbersome and time consuming, an easily implementable technique like ANFIS can be adopted. Thus, an ANFIS model has been proposed in this work to predict resistance factor in meandering open channel flow. This ANFIS results are found to be quite comparable to that of the observed values of the published data.

\section{Adaptive-Neuro Fuzzy Inference System (ANFIS)}

ANFIS, which is the abbreviation of adaptive neuro fuzzy inference system is an adaptive fuzzy system which works based on artificial neural network ability given in Jang [13]. A novel architecture which can serve as a basis for constructing a set of fuzzy if-then rules with appropriate membership functions to generate the stipulated input-output pairs, called Adaptive- Network-based Fuzzy Inference System, or simply ANFIS. This system is a fuzzy Sugeno by a forwarding network system. This fuzzy modeling first explored systematically by Takagi and Sugeno, has found numerous practical applications in control prediction and inference. However, there are some basic aspects of this approach, which are in need of better understanding. 


\subsection{Fuzzy rules and Fuzzy inference system}

The most characteristics of these methods are the ability of implementing human knowledge by tongue labels and fuzzy rules, nonlinearity of these systems and adaptability of these systems. A fuzzy system is a logical system based on if-then fuzzy rules. The inference system is based on the logical rules which images input variables space to output variable spaces using if-then statements and fuzzy decision making procedure. The fuzzy system is the Sugeno fuzzy system in which fuzzy rules stored in a rule base station. The rules in this system are

$$
\begin{aligned}
& \text { If } x_{1} \text { is } A_{1} \text { and } x_{2} \text { is } A_{2} \ldots x_{n} \text { is } A_{n} \\
& \text { Then } y=f\left[x_{1}, x_{2} \ldots x_{n}\right]
\end{aligned}
$$

where $A_{i}$ are the fuzzy sets.

In this system the if section of rule is a fuzzy rule and the result section of the rule is a real function of the input values and is a linear statement such as $\mathrm{a}_{1} \mathrm{x}_{1}+$ $\mathrm{a}_{2} \mathrm{x}_{2}+\ldots . .+\mathrm{a}_{\mathrm{n}} \mathrm{x}_{\mathrm{n}}$ (Dezfoli [14]). Basically a fuzzy inference system is composed of five functional blocks as given in Fig. 2.

\subsection{ANFIS architecture}

An equivalent ANFIS system is presented below in Fig. 8 (Tashnehlab and Menhaj [15]) and membership function used given in Fig. 9.Two inputs $\mathrm{x}$ and $\mathrm{y}$ and One output are taken in this system. Its rule is given by

$$
\begin{aligned}
& \text { IF } x \text { is the } A_{1} \text { and } y \text { is the } B_{1} \text { Then } f=p_{1} x+q_{1} y+r_{1} \\
& \text { IF } x \text { is the } A_{2} \text { and } y \text { is the } B_{2} \text { Then } f=p_{2} x+q_{2} y+r_{2}
\end{aligned}
$$

The basic learning rule of ANFIS is the back propagation gradient decent which calculates error signals (defined as the derivative of the squared error with respect to each nodes output) recursively from the output layer backward to the input nodes by Werbos [16]. This learning rule is exactly the same as the backpropagation learning rule used in the common feed-forward neural networks (Sadatpour et al. [17]). In train epoch the outputs of nodes (Fig. 10) is calculated at fourth layer, moving forward and then in next step after in backward movement the ratio of error is propagated over the parameters based on error descent gradient method according to Rumelhart et al. [18]. From ANFIS architecture it is observed that the given values of the of premise parameters, the overall output can be expressed as a linear combination of the consequent parameters.

\section{The input data sets}

For simulation of discharge in meander channel, proper value of roughness coefficient is very essential. For this purpose hydraulic and geometry data sets are required. Aspect ratio, sinuosity, longitudinal slope, Reynolds no, side slope (in degree) and roughness ratio are the input parameters and friction factor is the output for the present model development. Aspect ratio $(\alpha)$ is the ratio of channel 
width $(b)$ to flow depth $(h)$ in main channel. Roughness ratio $(\gamma)$ is the friction factor of a channel to the friction factor of a smooth channel $(f=0.015)$. Sinuosity $\left(S_{r}\right)$ is the ratio of channel length to valley length, refers to sinuous path of a channel. Along with the presently carried out experimental results also some literature is reviewed and finally a data set is prepared given in Table 2.

Table 2: $\quad$ Details of parameters.

\begin{tabular}{|c|c|c|c|c|c|c|c|}
\hline \multirow[t]{2}{*}{ Sl. No } & \multirow{2}{*}{ Sources of data } & \multicolumn{6}{|c|}{ Parameters } \\
\hline & & $\begin{array}{l}\text { Bed slope of } \\
\text { channel }\left(S_{0}\right)\end{array}$ & $\begin{array}{l}\text { Sinuosity } \\
\left(S_{r}\right)\end{array}$ & $\begin{array}{l}\text { Aspect } \\
\text { ratio }(\alpha)\end{array}$ & $\begin{array}{l}\text { Reynolds } \\
\text { No }\left(R_{e}\right)\end{array}$ & $\begin{array}{c}\text { Roughness } \\
\text { ratio }(\gamma)\end{array}$ & $\begin{array}{l}\text { Side } \\
\text { slope }\end{array}$ \\
\hline 1 & $\begin{array}{l}\text { Hydraulics Lab.NIT Rkl } \\
\text { (Khatua et al, 2011) }\end{array}$ & $\begin{array}{c}0.0019- \\
0.021\end{array}$ & $1-1.91$ & $\begin{array}{l}1.04- \\
10.90\end{array}$ & $\begin{array}{l}23665- \\
349516\end{array}$ & 1 & $\begin{array}{c}45- \\
90\end{array}$ \\
\hline 2 & $\begin{array}{l}\text { Hydraulics Lab.IIT Kgp } \\
\text { (Patra and Kar, 2000) }\end{array}$ & $\begin{array}{l}0.001- \\
0.0061\end{array}$ & $\begin{array}{c}1.043- \\
1.438\end{array}$ & $\begin{array}{c}0.49- \\
5.11\end{array}$ & $\begin{array}{l}56759- \\
779959\end{array}$ & $1-2$ & 90 \\
\hline 3 & $\begin{array}{l}\text { University of Bradford } \\
\text { (Shino \&Knight, 1999) }\end{array}$ & $\begin{array}{c}0.0005- \\
0.002\end{array}$ & $\begin{array}{c}1.092- \\
1.571\end{array}$ & $\begin{array}{l}2.88- \\
24.48\end{array}$ & $\begin{array}{l}41549- \\
527297\end{array}$ & 1 & 45 \\
\hline 4 & FCF channel & $\begin{array}{l}1.92817- \\
0.000996\end{array}$ & $1-1.21$ & $\begin{array}{l}4.46- \\
22.61\end{array}$ & $\begin{array}{l}62704- \\
802467\end{array}$ & $1-1.8$ & 45 \\
\hline 5 & $\begin{array}{l}\text { SERC Flood Facility at } \\
\text { HR Wallingford, U.K }\end{array}$ & 0.00073 & 1.37 & $\begin{array}{l}6.81- \\
15.25\end{array}$ & $\begin{array}{c}323225- \\
425255\end{array}$ & 1 & 45 \\
\hline 6 & $\begin{array}{l}\text { Channel of Willets and } \\
\text { Hardwick (1993) }\end{array}$ & 0.000621 & 2.04 & 2.78 & $\begin{array}{l}54231- \\
203476\end{array}$ & 1 & 45 \\
\hline 7 & s B extension, Glasgow & 0.00073 & 1.374 & $\begin{array}{l}2.67- \\
15.69\end{array}$ & $\begin{array}{c}564532- \\
652387\end{array}$ & $1-2$ & $\begin{array}{l}30- \\
90\end{array}$ \\
\hline 8 & $\begin{array}{l}\text { Natural Channel } \\
\text { (Non-Cohesive Sand ) }\end{array}$ & $\begin{array}{c}0.000996- \\
0.001021\end{array}$ & $1.3-1.5$ & $6-15$ & $\begin{array}{c}238452- \\
673284\end{array}$ & 2.8 & 45 \\
\hline 9 & $\begin{array}{l}\text { Natural Channel } \\
\text { (Cohesive Sand) }\end{array}$ & $\begin{array}{l}0.000996- \\
0.001021\end{array}$ & $1.4-1.8$ & $6-15$ & $\begin{array}{c}218752- \\
773514\end{array}$ & 2 & 45 \\
\hline
\end{tabular}

\section{Results and discussions}

In this section to verify the accuracy of the results further regression analysis is also carried out. Regression curves are plotted showing between actual DracyWeisbach $f$ and predicted Dracy-Weisbach $f$ through ANFIS model for training data and testing data respectively. It can be observed that data are well fitted because a high degree of coefficient of determination $\left(\mathrm{R}^{2}\right)$ as 0.927 for training (Fig. 11) and as 0.88 for testing data (Fig. 12) is obtained.

From the regression analysis it can be observed that ANFIS method showing maximum accuracy. By using the testing data set roughness value is calculated and the developed ANFIS model results perform well shown below (Fig. 13). 


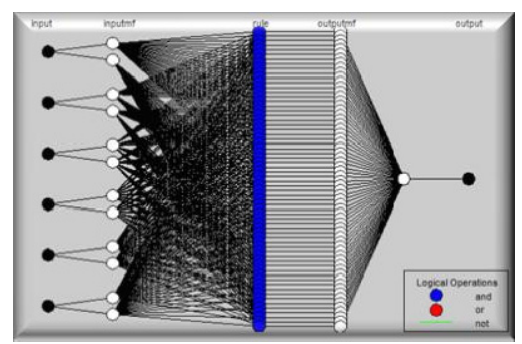

Figure 8: Architecture of developed ANFIS model.

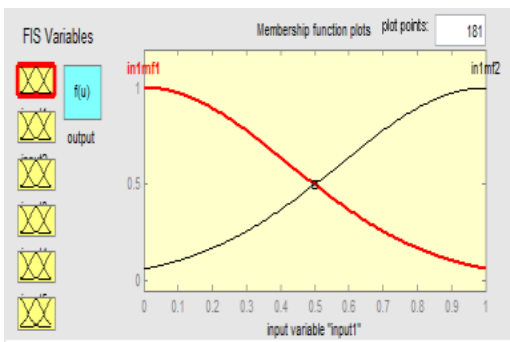

Figure 9: Membership function for output.

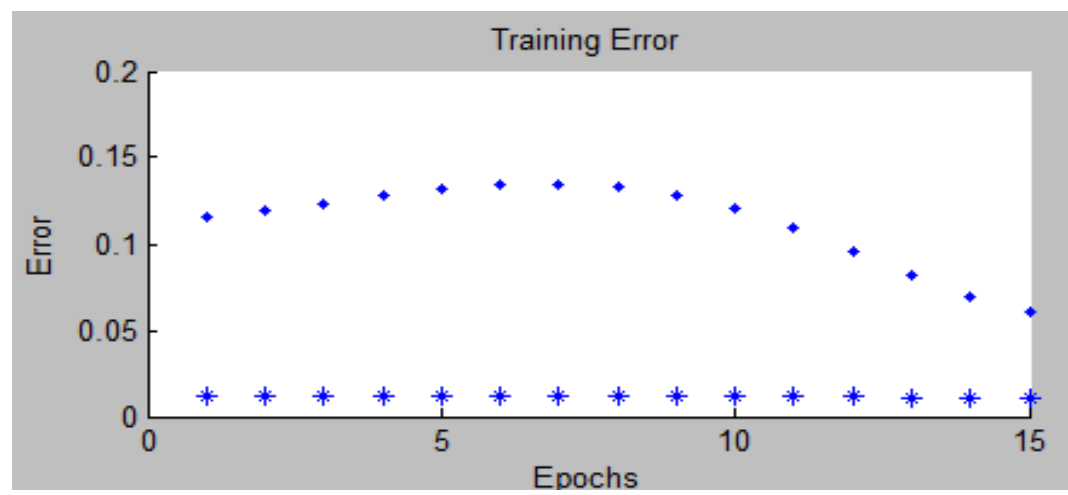

Figure 10: Training error with epochs.

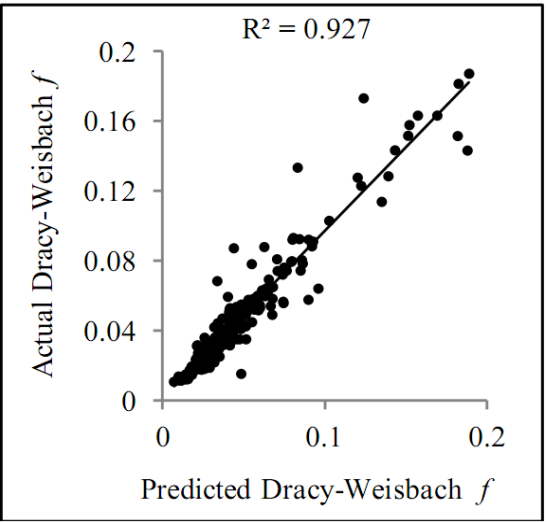

Figure 11: Co-relation plot of training data.

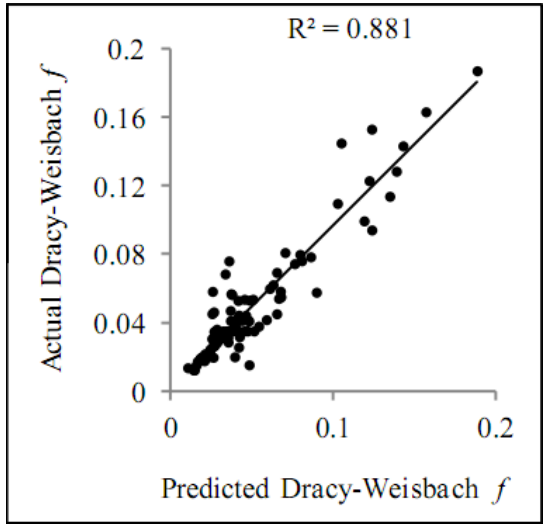

Figure 12: Co-relation plot of testing data. 


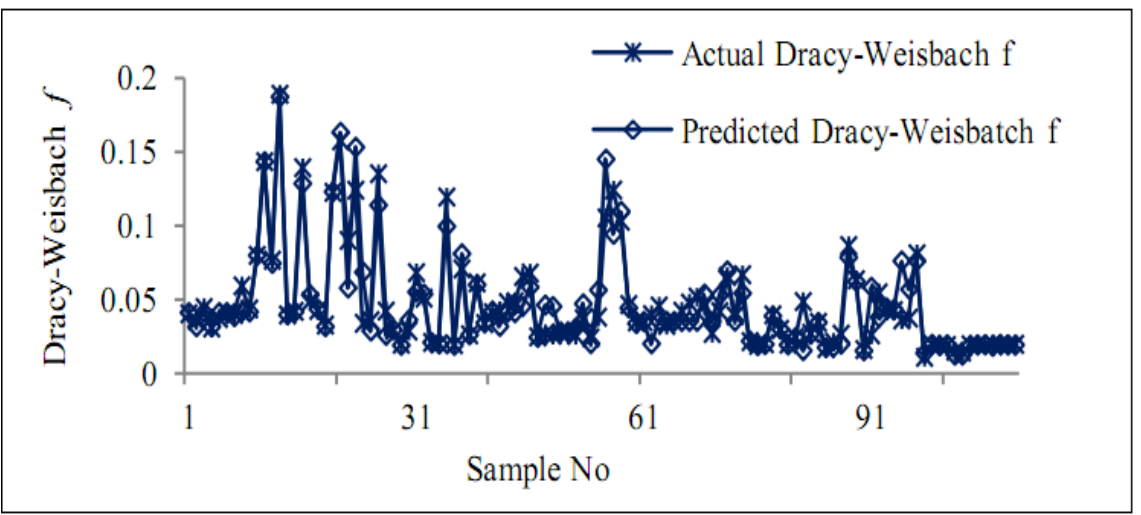

Figure 13: Matching figure of actual results and predicted ANFIS results.

\section{Conclusions}

- In a meandering channel the friction factor $f$ is found to be varying with aspect ratio, sinuosity, longitudinal slope, Reynolds no, side slope and roughness ratio. Therefore an assumption of average value of flow resistance coefficient for all depths of flow and for channels of different hydraulic and geometric conditions results in significant errors in discharge estimation.

- The experiment has been conducted to study the variation of friction factor with different geometrical, surface and hydraulic parameters of a meandering channel.

- Using the present experimental channel and global data sets an ANFIS model has been developed to predict friction factor $f$ of a meandering channel. The data are well fitted with high degree of coefficient of determination $\left(R^{2}\right)$ as 0.92 for training and as 0.88 for testing data. This model can be considered to predict the friction factor of a meandering open channel for both smooth and rough surface conditions effectively.

\section{Acknowledgement}

The support from Department of Science and Technology, Government of India for carrying out the experimental research work in the Hydraulics laboratory at National Institute of Technology, Rourkela is thankfully acknowledged.

\section{References}

[1] Sellin, R.H.J., “A Laboratory Investigation into the Interaction between Flow in the Channel of a River and that of its Flood Plain.” La Houille Blanche, No.7, pp. 793-801, 1964. 
[2] Shiono, K., Al-Romaih, J.S., and Knight, D.W., "Stage-Discharge Assessment in Compound Meandering Channels”, Journal of Hydraulic Engg. ASCE vol. 125, No.1. pp. 66-77, 1999.

[3] Patra, K.C, and Kar, S. K., "Flow Interaction of Meandering River with Floodplains”. Journal of Hydraulic Engrg., ASCE, 126(8), 593-604, 2000.

[4] Patra, K.C., and Khatua, K. K., "Energy Loss and Discharge Estimation in Two Stage Meandering and Straight Compound Channel”, EWRI of ASCE and IIT Kanpur, 2006.

[5] Khatua, K. K., Patra, K.C.\& Nayak P., "Meandering effect for evaluation of roughness coefficients in open channel flow" Sixth Int Conf on River Basin Management VI, pp. 213-227, Vol 146 of WIT Transactions on Ecology and the Environment (ISSN 1743-3541), and modified version is accepted for International Journal of CMEM (2012), WIT Press, 2011.

[6] Chow, Ven Te, “Open-Channel Hydraulics” New York, McGraw Hill Book Co, 1959.

[7] Cowan, W. L., “Estimating Hydraulic roughness Coefficients”. Agric. Engg, 37, pp. 473-475, 1956.

[8] Acrement, G. J., Jr. and Schneider, V. R., “Guide for selecting Manning’s roughness coefficients for natural channels and flood plains”. U.S. Geological Survey Water Supply paper 2339, Federal Center, Colo, 1989.

[9] "Hydraulic capacity of meandering channels in straight floodways". Tech. Memorandum No. 2-429, U.S. Army Corps of Engineers, Waterways Experiment Station, Vicksburg, Miss, 1956.

[10] "Guide for selecting roughness coefficient "n" values for channels". Soil Cons. Service, U.S. Dept. of Agric., Washington, D.C., 1963.

[11] James, C. S., and Wark, J. B., "Conveyance estimation for meandering channels”. Rep. SR 329, HR Wallingford, Wallingford, U.K., Dec., 1992.

[12] Maria, A.A, and da Silva A. F., "Friction Factor of Meandering Flows". Journal of Hydraulic Engineering, ASCE, Vol. 125, No. 7, pp. 779-783, 1999.

[13] Jang, J.-S.R., “ANFIS: adaptive-network-based fuzzy inference system”. IEEE Trans. Sys. Man Cybern. 23 (3), pp. 665-685, 1993.

[14] Dezfoli, K.A., "Principles of Fuzzy theory and its application on water engineering problems”, Jihad Press, Tehran, Iran, p. 227, 2003.

[15] M. Tashnehlab and S. Menhaj, "Modeling trip tours using ANFIS modeling”, Engineering Journal of Tehran University, 31(3), pp. 361370, 2001.

[16] Werbos, P. J., "Beyond Regression: New Tools for Prediction and Analysis in the Behavioral Sciences”. PhD thesis, Harvard University, 1974.

[17] Sadatpour, M. M. Afshar, A. Hadad, "Fuzzy optimized model for river water quality modeling”, Isfahan Journal of water and wastewater, Isfahan, Iran, No.64, pp. 15-27, 2005.

[18] Rumelhart, D. E., Hinton, G. E., and Williams, R. J., "Learning representations by back-propagating errors”. Nature, vol. 323, pp. 533536, 1986. 